\title{
Melanosis neurocutánea. Comunicación de un caso y revisión de la bibliografía
}

Neurocutaneous melanosis. Case report and literature review

\section{Dra. María Marta Buján ${ }^{a}$ Dra. Andrea Bettina Cervinia, Dra. Susana Pérsico y Dr. Adrián Martín Pierini}

\begin{abstract}
RESUMEN
La melanosis neurocutánea se caracteriza por la proliferación de melanocitos y depósitos de melanina en el sistema nervioso central asociada con nevos melanocíticos gigantes. Los pacientes con nevos melanocíticos congénitos gigantes localizados en el eje axial posterior (dorso, nuca o cabeza) o múltiples nevos melanocíticos congénitos pequeños son los que tienen mayor riesgo de presentarla.

En la mayoría de los pacientes la melanosis neurocutánea es asintomática y se detecta como un hallazgo en los estudios por imágenes; sin embargo, los casos que desarrollan síntomas tienen mal pronóstico y el óbito se produce antes de los 3 años de iniciados.

Se presenta una paciente con un nevo melanocítico congénito gigante y múltiples satelitosis, con compromiso asintomático del sistema nervioso central. Se destaca la importancia del seguimiento multidisciplinario de estos niños con el fin de detectar, en forma precoz, cualquier signo o síntoma neurológico que pudiesen desarrollar, como así también la presencia de melanoma.

Palabras clave: melanosis neurocutánea, nevo melanocítico congénito gigante, niños.
\end{abstract}

\section{SUMMARY}

Neurocutaneous melanosis is characterized by an increased number of melanocytes and melanin deposit in central nervous system associated with giant melanocytic congenital nevi. Patients with multiple satellite nevi or giant cutaneous melanocytic nevus in a midline location (overlying the back, neck or head) have more likelihood of having neurocutaneous melanosis. In most patients, the neurocutaneous melanosis is asymptomatic, only detectable by MRI; nevertheless, those patients with clinical manifestations have a poor prognosis, dying within 3 years of initial neurological manifestations.

We present a patient with giant melanocytic congenital nevi and multiple satellite nevi associated with asymptomatic neurocutaneous melanosis. We emphazise the importance of multidisciplinary evaluation in order to detect early neurological symptoms and/or melanoma.

Key words: neurocutaneous melanosis, giant congenital melanocytic nevus, children.

doi:10.5546/aap.2011.e109

a. Servicio de Dermatología.

b. Servicio de Diagnóstico por Imágenes.

Hospital Nacional de Pediatría "Prof. Dr. Juan P. Garrahan". Buenos Aires, Argentina.

Correspondencia:

Dra. María Marta Buján:

mariambujan@yahoo.com

Conflicto de intereses: Ninguno que declarar.

Recibido: 26-4-11

Aceptado: 15-6-11

\section{INTRODUCCIÓN}

La melanosis neurocutánea (MNC) es un rara enfermedad, caracterizada por la proliferación de melanocitos y depósitos de melanina en el sistema nervioso central (SNC) asociada a un nevo melanocítico congénito gigante o múltiples nevos melanocíticos satélites.

Presentamos una niña con un nevo melanocítico congénito gigante (NMCG) ubicado en dorso, múltiples nevos melanocíticos satélites con compromiso del SNC sin sintomatología neurológica hasta el momento de esta publicación.

\section{CASO CLÍNICO}

Paciente de 8 meses de vida que concurrió a la consulta por presentar un nevo melanocítico congénito gigante que ocupaba la totalidad del dorso con extensión hacia región anterior del tronco. Se trataba de una placa de más de $20 \mathrm{~cm}$, de coloración negruzca, con componente piloso en su parte inferior (Figura 1). A la palpación, el nevo era rugoso y áspero, con disminución del tejido celular subyacente y presencia de algunos nódulos subcutáneos compatibles con proliferaciones neuroides. Además, presentaba múltiples nevos melanocíticos satélites congénitos y adquiridos

Figura 1. Nevo melanocítico congénito gigante que compromete la totalidad del dorso

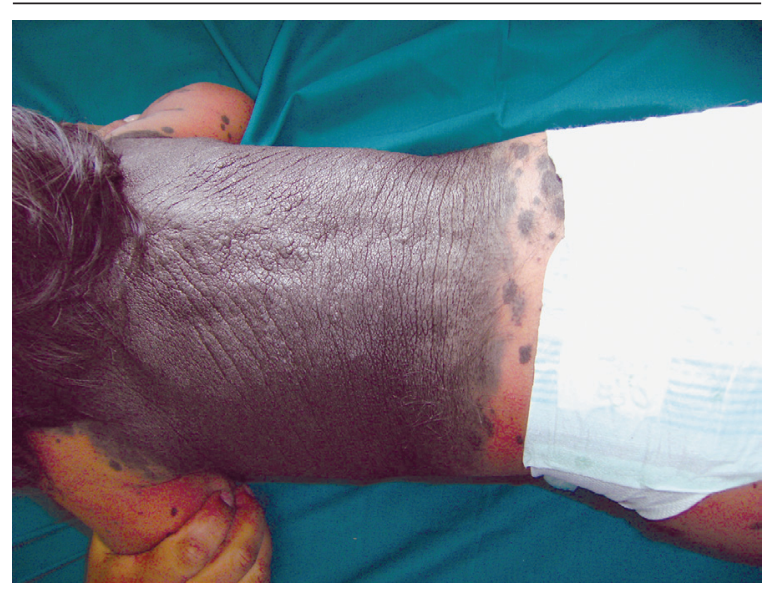


que comprometían la totalidad del tegumento ( $F$ gura 2), incluida la mucosa oral, palmas, plantas (Figura 3) y uña del hallux del pie derecho. El desarrollo neurológico era acorde a su edad; no presentaba visceromegalias ni adenopatías palpables.

Se realizaron los siguientes estudios complementarios:

- Estudio histopatológico: nevo melanocítico compuesto con rasgos congénitos.

- Resonancia magnética de cerebro y columna vertebral: múltiples focos de melanosis ubicados en ambos lóbulos temporales, cerebelo y protuberancia (Figura 4). Columna vertebral sin particularidades.

- Examen oftalmológico y fondo de ojo: normal.

FIGURA 2. Extensión anterior del NMCG de dorso y presencia de múltiples satelitosis en tronco, cara y miembros

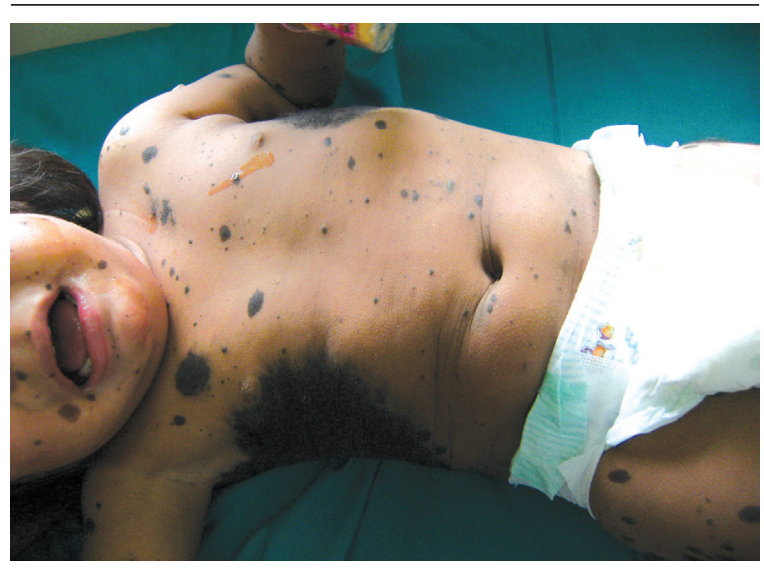

FIGURA 3. Satelitosis en ambas plantas de pie

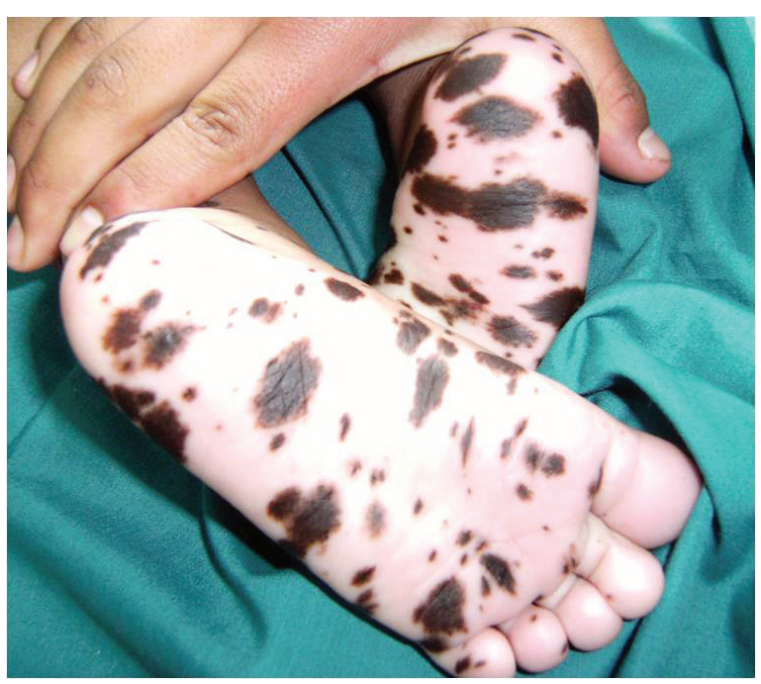

La paciente es evaluada periódicamente por los servicios de neurología, neurocirugía, dermatología y clínica pediátrica de nuestro Hospital. Actualmente tiene 3 años y, hasta el momento, no ha presentado síntomas neurológicos ni criterios para ser intervenida por el servicio de neurocirugía.

\section{DISCUSIÓN}

La melanosis neurocutánea (MNC) se caracteriza por la proliferación de melanocitos en el sistema nervioso central (SNC), asociada a un nevo melanocítico congénito gigante (NMCG) o satelitosis cutáneas. ${ }^{1-4}$ Fue descripta por primera vez en $1861 \mathrm{y}$, desde entonces, se han publicado pocos casos. En 1964, Fox estableció los siguientes criterios diagnósticos para definirla: 1) presencia de grandes o múltiples nevos congénitos asociados a melanosis o melanoma leptomeníngeo; 2) ausencia de melanoma en piel; 3) no evidencia de melanoma en ningún otro órgano fuera del SNC.5,6

Habitualmente, en el SNC se hallan melanocitos, que permanecen quiescentes y asintomáticos. En el caso de la melanosis neurocutánea, debido a un defecto durante el desarrollo embriológico, se produce la proliferación de células névicas con depósito anormal de melanina en el SNC. ${ }^{1,6}$

FIgURA 4. RMI de cerebro: Imágenes hiperintensas en ambos lóbulos temporales en $\mathrm{T1}$

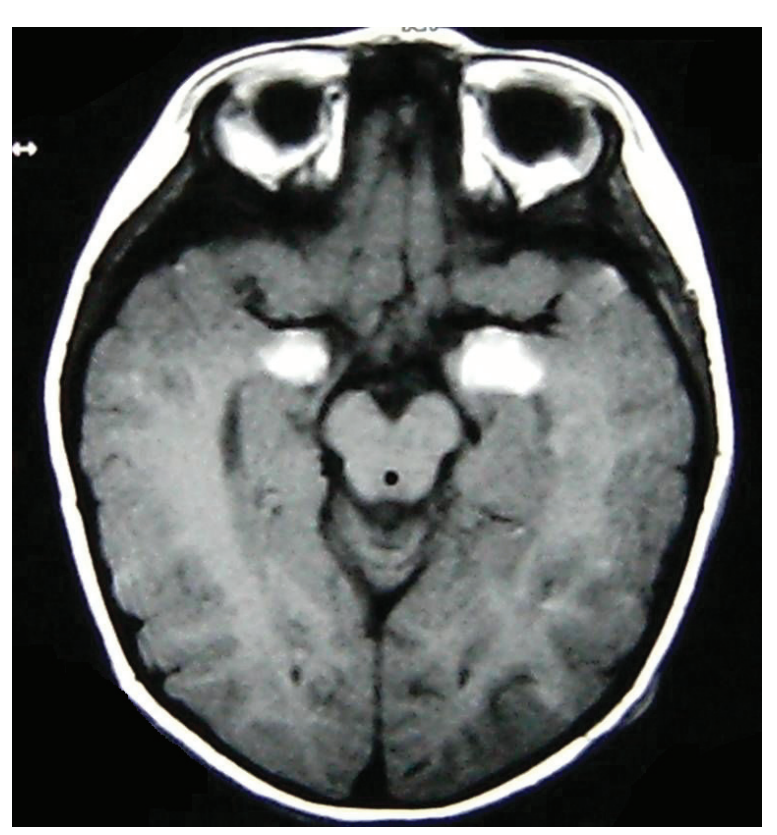


Se define a un nevo melanocítico congénito gigante como aquel cuyo diámetro mayor supera los $20 \mathrm{~cm}$ en la edad adulta. ${ }^{2,7-9}$ En los recién nacidos, se puede definir como NMCG a aquellos nevos que son mayores que la palma si se localizan en cabeza o cuello u ocupan más del $5 \%$ de la superficie corporal si están en tronco o miembros. ${ }^{8}$ Se considera satelitosis cuando el paciente presenta 3 o más nevos melanocíticos congénitos pequeños o medianos. ${ }^{2}$ La incidencia de los NMCG es de aproximadamente 1 en 20000 nacimientos. ${ }^{4,-11}$

El origen embriológico de la MNC no está bien establecido. Se cree debida a una alteración en la migración de los melanoblastos desde la cresta neural hacia la piel y las leptomeninges, con depósitos anormales y posterior proliferación de ellos, con producción de nevos melanocíticos congénitos, satelitosis o melanosis del SNC. ${ }^{3,5,11}$ Existen en la actualidad múltiples líneas de investigación acerca del origen de esta patología. Se cree que estarían involucradas mutaciones somáticas del protooncogen $c$ - Met o que existiría sobreexpresión del factor de crecimiento hepatocitario (el cual es un promotor de la proliferación y movilidad del melanocito), que causa una disrregulación en el crecimiento, diferenciación y migración de los melanoblastos. Nuevas investigaciones sobre los mecanismos de desarrollo, maduración y proliferación ayudarán a comprender mejor la vía de migración. ${ }^{8,11}$

La melanosis neurocutánea presenta una herencia esporádica, sin predilección de raza o sexo. ${ }^{5} \mathrm{Su}$ incidencia real es desconocida; ${ }^{2}$ según diferentes publicaciones oscila entre el 1-12\% de los pacientes con NMCG. ${ }^{12}$ Estas cifras varían según la presencia o no de síntomas neurológicos y del tipo de estudio realizado a los pacientes con NMCG. Los porcentajes más bajos corresponden a aquellas publicaciones en que sólo se estudiaron los pacientes con algún síntoma.

Los NMCG ubicados en la línea media posterior (extremidad cefálica, nuca o columna) y la presencia de múltiples satelitosis se asocian con mayor riesgo de presentar melanosis neurocutánea. ${ }^{1,3,8,11-13}$ Nuestra paciente presentaba tanto un NMCG en el dorso y extremidad cefálica como múltiples satelitosis.

Por fortuna, aproximadamente el $96 \%$ de las MNC son asintomáticas, siendo sólo un hallazgo en las neuroimágenes. ${ }^{4,9}$ Los síntomas en la MNC pueden manifestarse independientemente de la transformación maligna de las lesiones. ${ }^{3} \mathrm{Se}$ presentan generalmente dentro de los primeros 2 años de vida y se deben a la proliferación de los melanocitos; consisten en convulsiones, hidrocefalia, parálisis de los nervios craneales, signos de hipertensión endocraneana, de compresión raquídea o de masa ocupante, entre otros. ${ }^{1-5,9,14}$

Excepcionalmente se presentan en forma más tardía, alrededor de la $2^{\mathrm{a}}$ o $3^{\mathrm{a}}$ década de la vida, con aumento de presión endocraneana o trastornos conductuales. ${ }^{14}$ En los casos en que la melanosis neurocutánea es sintomática, su pronóstico es ominoso, incluso en ausencia de melanoma; la mayoría los pacientes (90\%) fallece dentro de los 3 años del inicio de los síntomas. $1,3,4,8,9,14$

El riesgo de transformación maligna de la melanosis del SNC no está aún bien determinado; algunos autores sostienen que tendrían el mismo riesgo que las lesiones cutáneas ${ }^{3}$ y otros describen hasta un $40-50 \%$ de riesgo de malignización. ${ }^{14}$

El estudio de elección para la búsqueda de melanosis del SNC es la resonancia magnética. ${ }^{3,6,9,12,15}$ Los hallazgos habituales son: depósitos de melanina en el cerebro (fundamentalmente lóbulos temporales, amígdala, tálamo y cerebelo) y engrosamiento de las leptomeninges. Los primeros se observan como imágenes hiperintensas sin contraste en T1; la afectación meníngea se evidencia luego de la administración de contraste endovenoso, que refuerza las leptomeniges afectadas. $1,2,9,14$

Otras anormalidades halladas en los pacientes con NMCG o melanosis neurocutánea son: malformación de Dandy-Walker; quistes de la fosa posterior; lipomas intraespinales; espina bífida; hipertrofia de los huesos del cráneo y escoliosis, por lo que los estudios por imágenes, además de pesquisar la presencia de melanosis, son de utilidad para detectar también cualquier tipo de anomalía estructural del SNC. 2,6,9

Además de realizar un estricto seguimiento clínico y neurológico es recomendable una RMI anual en pacientes asintomáticos o más tempranamente en caso de existir algún síntoma. ${ }^{1,4,9}$ Asimismo, es fundamental el seguimiento de las lesiones cutáneas por el riesgo de desarrollo de melanoma.

Los pacientes con melanosis neurocutánea sintomática pueden requerir tratamiento neuroquirúrgico (válvulas de derivación, descompresiones, extracciones quirúrgicas, etc.) o tratamiento radiante o quimioterápico. ${ }^{3}$

El tratamiento precoz no modificaría el pronóstico de estos niños, pero sí su calidad de vida.

\section{CONCLUSIÓN}

Ante un nevo melanocítico congénito gigante ubicado en el eje axial posterior o la presencia de 
satelitosis se deben realizar estudios por imágenes del SNC con el fin pesquisar la presencia de melanosis neurocutánea o malformaciones asociadas. En caso de que se confirme la presencia de melanosis neurocutánea y ésta sea sintomática, el tratamiento debe instaurarse lo más temprano posible con la finalidad de mejorar la calidad de vida.

En el caso de que la MNC sea asintomática, el seguimiento multidisciplinario debe ser estricto, con el fin de detectar cualquier cambio neurológico. Deberá incluir al pediatra de cabecera, dermatólogo, neurólogo, especialista en diagnóstico por imágenes y, eventualmente, neurocirugía.

Se debe recalcar, también, la importancia de los controles periódicos del NMCG y sus satelitosis, por el riesgo de desarrollo de melanoma.

\section{BIBLIOGRAFÍA}

1. Agero AL, Benvenuto-AndradeC, Dusza SW, Halpern AC, et al. Asymptomatic neurocutaneous melanocytosis in patients with large congenital melanocytic nevi: a study of cases from an Internet-based registry. J Am Acad Dermatol 2005; 53:959-65.

2. D'Argenio A, David P, Engohan C, Hennequin Y, et al. Neurocutaneous melanosis in a newborn with giant congenital melanocytic nevus. J Neuroradiol 2007; 34:272-5.

3. Arneja JS, Gosain AK. Giant congenital melanocytic nevi of the trunk and an algorithm for treatment. J Craniofac Surg 2005; 16:886-93.

4. Hale EK, Stein J, Ben-Porat L, Panageas KS, et al. Association of melanoma and neurocutaneous melanocytosis with large congenital melanocytic naevi. Results from the NYU-LCMN registry. Br J Dermatol 2005; 152:512-7.
5. Noronha L, Sampaio G, Netto MR, Reis-Filho JS, et al. Melanose neurocutânea [Neurocutaneous melanosis]. J Pediatr (Rio J) 1999; 75:277-80.

6. Cabrera H, García S. Síndromes con nevos nevocelulares. En: Cabrera H, García S. Nevos. Buenos Aires: Actualizaciones Médicas; 1998.Págs.83-84.

7. Lyon VB. Congenital melanocytic nevi. Pediatr Clin N Am 2010; 57:1155-76.

8. Pierini AM. Nevos melanocíticos congénitos gigantes. Propuesta sobre su manejo. Experiencia en 176 casos. Medicina Infantil 2003; 10:30-37.

9. Price HN, Schaffer JV. Congenital melanocytic nevi - when to worry and how to treat: facts and controversies. Clin Dermatol. 2010; 28:293-302.

10. Schaffer JV, Bologna JL. Congenital melanocytic nevi and speckled lentiginous nevi. [Acceso: 24-06-11] Disponible en: www.uptodate.com/contents/congenital-melanocytuc-nevi-and-speckkd-lentiginous-nevi?source=search result\&selectedtitle $=1 \% 7 \mathrm{E} 4$.

11. Marghoob AA, Dusza S, Oliveria S, Halpern AC. Number of satellite nevi as a correlate for neurocutaneous melanocytosis in patients with large congenital melanocytic nevi. Arch Dermatol 2004; 140:171-5.

12. Lovett A, Maari C, Decarie JC, Marcoux D, et al. Large congenital melanocytic nevi and neurocutaneous melanocytosis: one pediatric center's experience. J Am Acad Dermatol 2009; 61:766-74.

13. Fernandes NC, MachadoJL. Estudo clínico dos nevos melanocíticos congênitos na crianza e no adolescente: Clinical study of the congenital melanocytic naevi in the child and adolescent. An Bras Dermatol 2009; 84:129-35.

14. Bittencourt FV, Marghoob AA, Kopf AW, Koenig KL, et al. Large congenital melanocytic nevi and the risk for development of malignant melanoma and neurocutaneous melanocytosis. Pediatrics 2000; 106:736-41.

15. Kinsler VA, Chong WK, Aylett SE, Atherton DJ. Complications of congenital melanocytic naevi in children: analysis of 16 years' experience and clinical practice. Br J Dermatol 2008; 159:907-14. 